\title{
Service Personnel
}

National Cancer Institute

\section{Source}

National Cancer Institute. Service Personnel. NCI Thesaurus. Code C53273.

Qualified persons who have the appropriate technical expertise, training and experience necessary to provide assistance and support in medical device installation, maintenance, operation and repair. 